American Journal of Pharmaceutical Education 2020; 84 (11) Article 8418.

\title{
COMMENTARY
}

\section{Systemic Racism: Pharmacists' Role and Responsibility}

\author{
Vibhuti Arya, PharmD, MPH, ${ }^{\mathrm{a}}$ Lakesha Butler, PharmD, ${ }^{\mathrm{b}}$ Sandra Leal, PharmD, MPH, ${ }^{\mathrm{c}}$ \\ Lucinda Maine, PhD, ${ }^{\mathrm{d}}$ Nancy Alvarez, PharmD, ${ }^{\mathrm{e}}$ Natasha Jackson, PharmD, Alex C. Varkey, PharmD ${ }^{\mathrm{f}}$ \\ a St. John's University, College of Pharmacy and Health Sciences, Queens, New York \\ ${ }^{\mathrm{b}}$ Southern Illinois University, Edwardsville, Illinois \\ ${ }^{c}$ Tabula Rasa HealthCare, Moorestown, New Jersey \\ ${ }^{\mathrm{d}}$ American Association of Colleges of Pharmacy, Arlington, Virginia \\ ${ }^{\mathrm{e}}$ University of Arizona, College of Pharmacy, Tucson, Arizona \\ ${ }^{\mathrm{f}}$ Houston Methodist Hospital, Houston, Texas
}

Submitted June 23, 2020; accepted September 8, 2020; published November 2020.

\begin{abstract}
Systemic racism is a public health emergency and disproportionately impacts communities of color, specifically Black Americans. Pharmacists took an oath to protect the welfare of humanity and protect our patients. As such, to practice truly patient-centered care, pharmacists must recognize racism as a root cause of social determinants of health and use their privilege to educate themselves and their colleagues around dismantling structural racism.
\end{abstract}

Keywords: racism, structural racism, pharmacists

Systemic racism is a public health emergency and a root cause of social determinants of health. Social determinants of health, as described by Healthy People 2030, are "conditions in the environments in which people are born, live, learn, work, play, worship, and age that affect a wide range of health, functioning, and quality of life outcomes and risks." 1 These include factors such as education, built environments, employment, socioeconomic status, social networks, social norms and attitudes (eg, racism and discrimination), and access to health care, including wellness amenities. Academic and research programs have attempted to address social determinants of health; however, implementation of effective policies and sustainable programs to address systemic racism and the consequential social determinants of health remain unacceptably inadequate, largely under-resourced and underdeveloped, and even under-recognized in some cases. What is missing is the explicit recognition of the relationship among social determinants of health and systemic racism. Systemic racism (sometimes also referred to as structural racism) $)^{2}$ is "reflected in the policies, laws, rules, norms, and customs enacted by organizations and societal institutions that advantage whites as a group

Corresponding Author: Vibhuti Arya, St. John's University College of Pharmacy and Health Sciences, Queens, NY 11439. Email: vibhuti.arya@gmail.com

Note: The copyright for this article is shared by the American Journal of Pharmaceutical Education, the Journal of the American College of Clinical Pharmacy, and the Journal of the American Pharmacists Association. over groups of color."3 A deeper understanding of systemic racism is needed to address health disparities and social determinants of health in an effective and sustainable way.

The County Health Rankings Model, a program of the Robert Wood Johnson Foundation, has identified clinical care as only $20 \%$ of the health factors that affect health outcomes ${ }^{4}$ for individuals and populations. Physical environment (10\%) and social and economic factors (40\%) make up half of the factors that affect outcomes. In addition, these, along with clinical care factors such as access to care and quality of care, eventually have an impact on the health behaviors and outcomes of our patients. As proposed by the Health Impact Pyramid by Frieden, ${ }^{5}$ interventions focused on socioeconomic factors, as opposed to individual patient-focused clinical interventions, can have an increased impact at the population level. The Pharmacists' Patient Care Process, developed by several national pharmacy organizations as members of the Joint Commission of Pharmacy Practitioners, puts the patient at the center of care and specifically calls for assessing factors such as health literacy and access to medications. ${ }^{6}$ Yet, pharmacists and other clinicians have not traditionally been trained explicitly to understand and address social determinants of health, or understand systemic racism as a root cause.

Diversity and cultural competency training are required in the pharmacy curriculum and have been typically connected to health disparities. ${ }^{7}$ This has resulted in students and health professionals linking cultural diversity 


\section{American Journal of Pharmaceutical Education 2020; 84 (11) Article 8418.}

to negative outcomes and experiences without addressing the root cause, especially if they have not made the connection to the root. ${ }^{8}$ Education on the connection among health disparities, social determinants of health, and systemic racism has been limited; thus, health disparities in the United States have continued to persist. Some pharmacists may not be aware of the differences in terminology related to equitable health care. Training in these differences along with direction on ways to support patients would give pharmacists the ability to create an impact on helping their patients overcome issues that create inequities in the health care they receive.

\section{KEY POINTS}

\section{Background:}

- Racism is a root cause of social determinants of health.

- Structural racism has been perpetuated through laws and policies, implicitly and explicitly, and continues to manifest in racial inequities across all parts of society, including education, health care, and social and political systems.

\section{Findings:}

- In order to practice patient-centered care, pharmacists must acknowledge and work to mitigate the negative impacts of social determinants of health.

- Pharmacists across all sectors must take a look inward at their own biases and socialization to then practice outward in dismantling structural racism in order to pave way for reform and racial equity.

In addition, pharmacists who identify as Black, Indigenous, Persons of Color (BIPOC) are typically left to solely carry the load of the work associated with leading diversity initiatives, committees, and task forces at their organizations when what is required is for non-BIPOC individuals to also engage in the work. In addition to such cultural taxation, BIPOC individuals are also subject to racism within, and external to, their work environments, including having their work minimized by colleagues, and having to face racial discrimination from patients, intersectionality of other forms of discrimination (eg, with issues of race and gender), and impact of past trauma from manifestations of centuries of legal discrimination and systemic racism in their daily lives. BIPOC pharmacists must be intentionally supported through organizational policies and processes, including providing safe spaces and support to speak up when they are experiencing racial discrimination, or have concerns about areas related to this, either for themselves or for their patients. These systems must be protected from potential retaliation. In addition, non-BIPOC colleagues need to be equipped with tools and methods for understanding the issues, which will in turn allow them to meaningfully engage in the work required to dismantle systems created to disadvantage BIPOC individuals. Thus, a re-examination of the impact of racism both within the profession and external to the profession (eg, toward patients) is warranted.

In education, this is the time to have honest conversations with students, faculty, staff, and alumni to identify ways in which we can understand how our own socializations and biases perpetuate systemic racism. It is also important to understand how each of us can address and actively fight against systemic racism within our communities and truly practice patient-centered care. The American Association of Colleges of Pharmacy (AACP) created a special task force on "Diversifying our Investment in Human Capital" that took a holistic look and made substantive recommendations on diversity, equity, and inclusion initiatives at all levels of pharmacy education. ${ }^{9}$ Recommendations included the need to increase the resources, both within the association and at schools and colleges of pharmacy, to improve student and faculty recruitment of BIPOC talent, and to improve the climate for learning, scholarly activities, and success at our institutions. The task force called for an increased emphasis on the roles of pharmacists in health equity and in addressing social determinants of health.

As practitioners, we must create the sustained time and space for dialogue that allows us to pay attention to patient and family needs, focus on how social determinants are affecting our patients' abilities to access and navigate care, and determine the best ways in which pharmacists can use their privilege to actively engage and dismantle structural racism. As researchers, it is imperative to understand the deep roots of racism that have created racial superiority as a false construct, how communities of color have been affected by research, and how we can actively work toward addressing gaps in data and opportunities to truly address population health in a positive manner through meaningful research and publication opportunities. A common thread in all of these aspects of education, practice, and research is understanding how we, as individuals and collectively, can change the narratives to actively include diverse perspectives to be impactful and advance access to care, increase quality, and decrease cost-for all. In addition, investing in education has to begin early by creating a pipeline for recruitment of students from under-represented communities. The latest numbers from AACP indicate that only $16.2 \%$ of all Doctor of Pharmacy students in the United States were in the under-represented minority category. ${ }^{10}$ Intentional recruitment of students who represent the communities they serve should be prioritized to help advance patient care, science, and equity. 


\section{American Journal of Pharmaceutical Education 2020; 84 (11) Article 8418.}

The issue of systemic racism not only affects our pipeline, our education, and our research, but also our leadership and our organizational policies and procedures to the very core. As the world is struggling to recover from a global pandemic that has already magnified the negative impact of social determinants of health and inequities in care among communities of color, systemic racism across the world is evident now more than ever. In a recently published review of public data, it was found that although nearly $20 \%$ of U.S. counties are considered disproportionately Black, those same counties accounted for more than half of the coronavirus disease (COVID-19) diagnoses, and almost $60 \%$ of the COVID-19 deaths nationally. ${ }^{11}$ Although the protests of late have also shifted the attention of many to violence and destruction, it is our responsibility to change the narrative to acknowledge the long-standing destruction of human rights and the basic welfare of marginalized communities, especially considering the historic treatment of Black people in the United States. Recognizing and fulfilling the Oath of the Pharmacist to consider the welfare of humanity and relief of human suffering as our primary concerns, we have a responsibility to demand and activate actionable and sustainable change. It is not enough for leaders to hire more BIPOC talent into their respective organizations. Health care leaders must also commit to a systematic review of all policies and procedures that affect both internal workings and external services provided by health care organizations to eliminate the deconstructive effects of systemic racism on public health and on the practitioners who have sworn to serve the public. Pharmacy leaders in the workplace must also review their own organizational and departmental structures and operations to determine ways to actively combat systemic racism and its impact on pharmacy services to the public.

We fully recognize that implementing policies and programs to focus on addressing these social determinants require time and commitment on the part of policy makers, decision makers, and leaders within and external to our profession. We also acknowledge that there are other external pressures on the profession and needs such as continued advocacy for recognition within the Social Security Act that would facilitate the ability to provide pharmacist patient-care services. Nonetheless, pharmacists must stand in solidarity to educate ourselves, step back, and make room for diverse perspectives to be part of our leadership and decision-making. In addition, we must actively seek true community engagement within our respective settings so that we may empower communities to be engaged in shared decision-making rather than the traditional voyeuristic approach to "helping" or "fixing" communities on the basis of our own limited understanding of what our communities actually want or need. Instead of being outcomes-driven to focus on immediate productivity, as pharmacists, it is our responsibility, with consideration for the welfare of our patients, to think about sustained outcomes and focus on the quality of projects and research so that we may move to tangible action for reforming systems plagued by racism.

\section{CONSIDERATIONS FOR ACTION AS A STARTING POINT}

1. Recognize and take individual responsibility to deepen our awareness around structural racism and its impact on our patients and communities over time.

2. Build the pipeline for future pharmacists to engage traditionally under-represented groups and, using census and pharmacist workforce data, identify how schools and colleges of pharmacy can enhance recruitment efforts so that students are representative of the communities they serve.

3. Create sustained space for students, practitioners, preceptors, and individuals holding positions of leadership to engage in dialogue around antiracism, implicit bias, and how they may collectively work toward actively dismantling structural racism.

4. Develop the requirement for education and training as part of Accreditation Council for Pharmacy Education standards to include antiracism and implicit-bias education in the pharmacy curriculum across all accredited programs.

a. Inventory what schools and colleges of pharmacy are doing in the areas of racial equity and diversity within the curriculum.

b. Enable content sharing, including lessons learned, where schools and colleges of pharmacy have developed strategic or action plans.

5. Establish equity in leadership to create opportunities for BIPOC individuals and create processes for supporting them through mentorship, resources, and shared decision-making.

6. Form specific task forces or committees to lead antiracism efforts, and create a position such as Director of Diversity or Chief Diversity Officer, and support these positions with mentorship, adequate financial and other resources, autonomy, and direct reporting lines to the CEO, dean, health sciences, and university as appropriate for strategic impact.

a. Ask BIPOC individuals for their support within these task forces or committees, and acknowledge the value they bring to the group on the 


\section{American Journal of Pharmaceutical Education 2020; 84 (11) Article 8418.}

basis of their lived experiences; the development of racial literacy and skills is recommended for effective and sustainable practice rather than appointing BIPOC individuals without support or decision-making.

b. Inventory how many schools and colleges of pharmacy already have established such infrastructure and facilitate formal organization of this group to provide space for sharing, including lessons learned.

7. Review and revise organizational policies and standard operating procedures to ensure that they are equitable.

8. Establish equity in faculty hiring and retention to better represent BIPOC individuals.

9. Engage patients and communities: Organizations as well as schools and colleges of pharmacy must engage in shared decision-making, ${ }^{12}$ and solicit input from the community around priorities for programs and services (eg, community outreach, educational programs, quality measures); this avoids the voyeuristic approach that engages communities passively with built-in assumptions as to what community needs are. Having a diverse student, faculty, staff representation will also aid in meaningful community engagement.

10. Review of policies of professional member organizations to identify policy gaps and opportunities to strengthen positions related to diversity and equity.

11. Strengthen advocacy efforts of organizations to include diversity and equity matters as they affect health care and the citizens of communities.

Although we acknowledge that these suggestions represent a major commitment on the part of the profession and its leaders, it is past time to address the issues of structural racism and associated social determinants of health. Pharmacists are uniquely positioned within their communities and across various practice settings to create an impact on patients' lives; schools and colleges of pharmacy express missional commitments to improve public health. Collectively, we can make a difference to create a positive impact on the lives of our patients, each other, and our future pharmacists.

\section{REFERENCES}

1. Social determinants of health. Healthy People 2030. https:// health.gov/healthypeople/objectives-and-data/social-determinantshealth. Accessed August 31, 2020.

2. The Aspen Institute. 11 terms you should know to better understand structural racism. https://www.aspeninstitute.org/blogposts/structural-racism-definition/. Accessed August 21, 2020.

3. Bell LA, Funk MS, Joshi KY, Valdivia M. Racism and white privilege. In: Adams M, Bell LA, Goodman DJ, Joshi KY, eds. Teaching for Diversity and Social Justice. $3^{\text {rd }}$ ed. New York, NY: Routledge; 2016:133.

4. County health rankings model: a Robert Wood Johnson Foundation program. https://www.countyhealthrankings.org/ explore-health-rankings/measures-data-sources/county-healthrankings-model. Accessed June 15, 2020.

5. Frieden TR. A framework for public health action: the health impact pyramid. Am J Public Health. 2010;100(4):590-595.

6. Joint Commission of Pharmacy Practitioners. Pharmacists' patient care process. https://jcpp.net/wp-content/uploads/2016/03/ PatientCareProcess-with-supporting-organizations.pdf. Accessed June 15, 2020.

7. Accreditation Council for Pharmacy Education. Accreditation standards and key elements for the professional program in pharmacy leading to the Doctor of Pharmacy degree ("Standards 2016"). https://www.acpe-accredit.org/pdf/

Standards2016FINAL.pdf. Accessed August 18, 2020.

8. Rockich-Winston N, Wyatt TR. The case for culturally responsive teaching in pharmacy curricula. Am J Pharm Educ. 2019;83(8):7425. 9. White C, Conway JM, Davis PK, et al. AACP special taskforce white paper on diversifying our investment in human capital. $A m J$ Pharm Educ. 2017;81(8):S13.

10. American Association of Colleges of Pharmacy. Academic pharmacy's vital statistics. https://www.aacp.org/article/academicpharmacys-vital-statistics. Accessed August 17, 2020.

11. Millett GA, Jones AT, Benkeser D, et al. Assessing differential impacts of COVID-19 on black communities. Ann Epidemiol. 2020; 47:37-44.

12. New York City Department of Health and Mental Hygiene. Community Engagement Framework May 2017. https://www.ccf.ny. gov/files/6615/3486/2005/NYC_DHMH_Community_Engagement_ Framework_document.pdf. Accessed June 15, 2020. 